\title{
In Vitro Susceptibility of Diabetic Wound Bacteria to Mixtures of Honey, Commiphora molmol and Nigella sativa
}

\author{
Hasan A. Alzahrani ${ }^{1}$, Balkees A. Bakhotmah ${ }^{1}$ and Laïd Boukraâ ${ }^{1,2, *}$ \\ I"Mohammad Hussein Al Amoudi Chair for Diabetic Foot Research" King Abdulaziz University, Jeddah, Saudi Arabia \\ ${ }^{2}$ Institute of Veterinary Sciences, Ibn-Khaldun University of Tiaret, 14000 Algeria
}

\begin{abstract}
The search for an ideal dressing for diabetic foot wounds/ulcers is still ongoing. Patients' preferences of such dressing usually relate to their local cultural background. The aim of this study was to evaluate the antibacterial effectiveness of some natural herbal medicines and honey mixtures on clinical isolates from diabetic wounds. Six mixtures consisting of honey, Commiphora molmol and Nigella sativa at different concentrations have been prepared (NP1 to NP6). All mixtures were effective against the tested bacterial isolates from three different diabetic food wound patients at $50 \%$. NP4 and NP5 were the most effective as antibacterial for the examined seven bacterial isolates among the mixtures as they were able to kill bacteria at $25 \%$ after 24 hours of incubation. An over additive action has been noticed between honey and herbal medicines. The effectiveness of mixtures was dose-dependent of Commiphora molmol; NP5 contained the highest amount of the later. Further research is needed to elucidate and optimize the effective combination of these natural products in clinical practice.
\end{abstract}

Keywords: Antibacterial, commiphora molmol, nigella sativa, diabetes.

\section{INTRODUCTION}

Diabetes is a chronic debilitating medical condition which is reaching epidemic proportions in Saudi Arabia. At least one out of five Saudis is affected [1] and selfmedication with oral natural preparations and herbs are fairly common across the country as part of complementary and alternative medicine (CAM) [2-4]. Foot disorders are among the most feared complications of diabetes [5] and the ultimate endpoint of diabetic foot ulcer is amputation if not well treated [6]. When amputation happens, it is usually associated with significant mortality [7-9], in addition to immense social, psychological and financial consequences $[10,11]$.

Medicinal plants are used in developing countries where it is believed to have lesser side effects and lower cost [12]. Moreover, its use depends on many factors including cultural background, education, socioeconomic factors, and nature of health problem and availability of the remedies in the local market.

Honey is one of the most widely used natural products not only in Saudi Arabia but also in all Arabian countries. It has been used since ancient times as a remedy in wound care. Honey has potent antibacterial activity and is effective in preventing and clearing wound infections [13]. Topical honey was shown to be effective in treating postoperative skin wounds in neonates that had failed to respond to antibiotic therapy [14]. It has been demonstrated in many studies

*Address correspondence to this author at the Researcher in "Mohammad Hussein Al-Amoudi Chair for Diabetic Foot Research", KAU, Jeddah, Saudi Arabia; Tel: +213 7 95306930; Fax: +213 46 454214;

E-mail: laid_bouk@hotmail.com that the antibacterial effects of honey are attributed to its high osmolarity, low $\mathrm{pH}$, hydrogen peroxide content, and presence of other uncharacterized compounds [15]. In Saudi Arabia, some herbs, natural products and CAM preparations are occasionally added to honey or used separately by diabetics.

Commiphora Molmol (Myrrh) is one species of the resinbearing plants which grows across the Red Sea in the area that is now Somalia and Ethiopia, while the collection of the gum resins was initiated in Arabia. Myrrh and many other species of Commiphora are becoming recognized to possess significant medicinal properties. Evidence-based researches have reported that these properties are directly attributable to terpenoids (especially furanoses-quiterpenes), the active compounds present in myrrh essential oil. Very recently, current studies have focused on applying clinical trial methodologies to validate its use as an antineoplastic, an antiparasitic agent, and as an adjunct in healing wounds [16, 17]. It was used to treat skin infections and periodontal abscesses [17]. It has also shown antibacterial and antifungal activity against standard pathogenic strains of Escherichia coli, Staphylococcus aureus, Pseudomonas aeruginosa and Candida albicans [18].

Nigella sativa (Black seed) has been used for medicinal purposes for centuries either as an herb or pressed into oil. It contains both fixed and essential oils, proteins, alkaloids and saponin [19]. Much of the biological activity of the seeds is attributed to thymoquinone. It has been reported that the later protects against nephrotoxicity and hepatotoxicity induced by either disease or chemicals [20]. Different crude extracts of Nigella sativa have shown effectiveness against multiantibiotic resistance bacterial isolates [21]. Therefore, the aim of the present study is to evaluate the antibacterial effec- 
tiveness of some natural mixtures of honey, Myrrh and black seed against bacteria isolated from diabetic foot ulcers and wounds.

\section{MATERIALS AND METHODS}

\section{Natural Preparations (NPs)}

Five NPs were prepared by mixing honey (Acacia honey, produced by Langanese Honig, Bargteheide, Germany) to Commiphora molmol and Nigella sativa (produced by $\mathrm{Al}$ Marjal Al Khalejiyah, Qasim, Saudi Arabia) at different concentrations. The sixth NP was honey alone Table 2. All NPs were prepared freshly and stored in dark at $4{ }^{\circ} \mathrm{C}$. The amounts used were based on authors' experience and local patients' preferences pattern.

\section{Clinical Microbial Isolates}

Tissues and deep wound aspirates were collected from three patients with clinically infected diabetic feet admitted to the King Abdulaziz University Hospital (KAUH). All of three patients were not on antimicrobial drugs for at least 3 days before collecting the specimens. The specimens were cultured in the Clinical Microbiology Laboratory at KAUH. A total of seven microorganisms were isolated from the three patients and identified biochemically.

\section{Bacterial Identification}

Three microorganisms were isolated from the first patient which were; Staphylococcus aureus, an extended spectrum beta-lactamase (ESBL)-producer Escherichia coli and Proteus mirabilis. Two bacterial strains were isolated from the second patient, namely Streptococcus pyogenes and Morganella morganii. Methicillin-resistant Staphylococcus aureus (MRSA) strain was isolated from the third patient by performing a susceptibility test to Methicillin.

\section{Broth Dilution Method}

For each of the six NPs; four sterile test tubes were labeled as following; $100 \%, 50 \%, 25 \%$ and $12.5 \%$. Using a sterile pipette, $1 \mathrm{ml}$ of each $\mathrm{NP}$ was transferred into the $100 \%$ test tube (TT). A total of $1 \mathrm{ml}$ of the nutrient broth was transferred into each of other TTs. Then, $1 \mathrm{ml}$ of the tested NP was transferred into the 50\% TT. After enough mixing, a total of $1 \mathrm{ml}$ of the mixture was transferred into the next TT. Same procedures were repeated until the $12.5 \% \mathrm{TT}$, from which, after well mixing, a total of $1 \mathrm{ml}$ was discarded.

A microbial suspension of 5-6 $\times 10^{5} \mathrm{CFU}$ (colony-forming unit) was made for each clinical isolate by transferring $1 \mathrm{ml}$ of its $0.5 \mathrm{McF}$ arland suspension into $9.0 \mathrm{ml}$ of nutrient broth, after enough mixing, a total of $10 \mu \mathrm{l}$ was inoculated into each TT of the different concentrations. A positive control was made by inoculating $10 \mu \mathrm{l}$ of the microbial suspension into $1 \mathrm{ml}$ of the nutrient broth. A negative control was made by adding $0.5 \mathrm{ml}$ of the nutrient broth to $0.5 \mathrm{ml}$ of the tested NP. For each TT, after well mixing, sub-culture was done immediately (i.e. at 0 hour time) and after 24 hours incubation $\left(\right.$ at $35^{\circ} \mathrm{C}$ ) by taking a loopful of the culture medium and inoculating it into a fresh blood agar plate (BAP). All BAPs were incubated at $35^{\circ} \mathrm{C}$ aerobically for 24 hours. The minimum bactericidal concentration (MBC) was read as the least concentration showing no growth (on the sub-cultured BAPs) after 24 hours incubation of the TT. All tests were performed in triplicate and were repeated three times to obtain reliable results.

\section{RESULTS}

For the microbial isolates of the first patient; the antibacterial effects on Staphylococcus aureus showed that NP4 and NP5 were the most effective as their $25 \%$ concentration was enough to kill the microorganism after 24 hours incubation. The other NPs were effective at 50\% concentration Table $\mathbf{1 .}$ For the ESBL-producer Escherichia coli; all of the six NPs showed the same bactericidal effect at $25 \%$ concentration which was enough to kill the microorganism after 24 hours. For Proteus mirabilis; NP6 (honey alone) was the most effective as the $25 \%$ was enough to kill most of the microorganism with few colonies (1 colony) grown after 24 hours incubation. The $50 \%$ concentration of each of the NPs was enough to kill the microorganism after 24 hours incubation.

Table 1. The Antibacterial Effectiveness of Natural Preparations (NPs) Against the Clinical Isolates

\begin{tabular}{|c|c|c|c|c|c|c|c|c|c|c|c|c|c|c|c|c|c|c|c|c|c|c|c|c|}
\hline \multirow{2}{*}{$\begin{array}{l}\text { Concentra- } \\
\text { tions of NPs } \\
\text { Number Of } \\
\text { Colonies }\end{array}$} & \multicolumn{6}{|c|}{$100 \%$} & \multicolumn{6}{|c|}{$50 \%$} & \multicolumn{6}{|c|}{$25 \%$} & \multicolumn{6}{|c|}{$12.5 \%$} \\
\hline & NP1 & NP2 & NP3 & NP4 & NP5 & NP6 & NP1 & NP2 & NP3 & NP4 & NP5 & NP6 & NP1 & NP2 & NP3 & NP4 & NP5 & NP6 & NP1 & NP2 & NP3 & NP4 & NP5 & NP6 \\
\hline S. aureus & NG & NG & NG & NG & NG & NG & NG & NG & NG & NG & NG & NG & $>100$ & $\underline{64}$ & $\underline{21}$ & NG & NG & 89 & $>100$ & $>100$ & $>100$ & $>100$ & $\underline{80}$ & $>100$ \\
\hline E. coli $\mathrm{ESBL}$ & NG & NG & NG & NG & NG & NG & NG & NG & NG & NG & NG & NG & NG & NG & NG & NG & NG & NG & $>100$ & $>100$ & $>100$ & $>100$ & $>100$ & $>100$ \\
\hline $\begin{array}{l}\text { Proteus } \\
\text { mirabilis }\end{array}$ & NG & NG & NG & NG & NG & NG & NG & NG & NG & NG & NG & NG & $\underline{19}$ & $\underline{13}$ & $\underline{93}$ & $\underline{60}$ & $\underline{84}$ & 1 & $>100$ & $>100$ & $>100$ & $\underline{55}$ & $\underline{92}$ & $>100$ \\
\hline $\begin{array}{l}\text { Strep. } \\
\text { pyogenes }\end{array}$ & NG & NG & NG & NG & NG & NG & NG & NG & NG & NG & NG & NG & NG & NG & NG & NG & NG & 95 & $>100$ & $\underline{51}$ & $\underline{13}$ & $\underline{68}$ & NG & $>100$ \\
\hline $\begin{array}{l}\text { Morg. } \\
\text { morganii }\end{array}$ & NG & NG & NG & NG & NG & NG & NG & NG & NG & NG & NG & NG & NG & NG & NG & NG & NG & NG & $>100$ & $>100$ & $\underline{40}$ & $\underline{80}$ & NG & $>100$ \\
\hline MRSA & NG & NG & NG & NG & NG & NG & NG & NG & NG & NG & NG & NG & NG & NG & NG & NG & NG & NG & $>100$ & $>100$ & $\underline{5}$ & $>100$ & $>100$ & $>100$ \\
\hline
\end{tabular}

$\mathrm{NG}=$ No growth . 
Table 2. Composition of the Six Natural Preparations

\begin{tabular}{|c|c|c|c|}
\hline & Honey (g) & Commiphora molmol & Nigella sativa \\
\hline \hline NP1 & 100 & $1 / 2$ ts & 0 \\
\hline NP2 & 100 & $1 / 2$ ts & $1 / 2$ ts \\
\hline NP3 & 100 & 1.0 ts & $1 / 2$ ts \\
\hline NP4 & 100 & 1.5 ts & $1 / 2$ ts \\
\hline NP5 & 100 & 2 ts & $1 / 2$ ts \\
\hline NP6 & 100 & 0 & 0 \\
\hline
\end{tabular}

Commiphora molmol: 1 ts $=2.50 \mathrm{~g}$

Nigella sativa; $1 \mathrm{ts}=3.42 \mathrm{~g}$

For the clinical isolates of the second patient; the antibacterial effects on Streptococcus pyogenes showed that NP5 was the most effective as the $12.5 \%$ concentration was enough to kill the microorganism after 24 hours incubation. All of the other NPs were effective at $25 \%$ concentration. For Morganella morganii; also NP5 was the most effective as the $12.5 \%$ concentration was enough to kill the microorganism after 24 hours incubation. All of the other NPs were effective at $25 \%$ concentration.

For the MRSA isolate of the third patient, NP3 was the most effective as the $12.5 \%$ concentration was enough to kill most of the microorganism with few (5) colonies grown after 24 hours incubation. The NP5 has shown the higher overall antibacterial effectiveness. All inoculated blood agar plates at 0 hour time were positive.

\section{DISCUSSION}

With increasing interest in the use of alternative therapies and as the development of antibiotic-resistant bacteria spreads, honey and medicinal plants may receive renewed recognition as wound healers. Both natural products are individually effective against bacteria, although joint use in wounds has not been reported. Isolation of multi-drug resistant strains is a common problem in hospitals and their current prevalence has led to a re-evaluation of the therapeutic use of ancient remedies, including honey and medicinal plants. Honey offers broad-spectrum antimicrobial properties and promotes rapid wound healing [22], but the mechanisms by which these effects are achieved have not been fully elucidated

In the present study, honey was the most effective NP against Proteus mirabilis as the $25 \%$ concentration was enough to kill most of the microorganism with only one colony grown after 24 hours incubation. The $50 \%$ concentration of each of the six NPs was enough to kill the microorganism after 24 hours incubation.

The results of this study showed that adding honey to Commiphora molmol and Nigella sativa increases the antibacterial effect against the clinical isolates. It seems that there is an over-additive action between honey and the tested medicinal plants; this action is also called synergism [23]. The exact mechanism of synergy between medicinal plants and honey is unclear. Clinical trials using a mixture of honey and these plants to treat diabetic wounds could further confirm the findings of this work.

The results also showed that the antibacterial effectiveness of the preparation depends on its amount of Commiphora molmol. Therefore, the most effective preparation was NP5 followed by NP4. The $12.5 \%$ concentration of NP5 was enough to kill Streptococcus pyogenes and Morganella morganii. The $25 \%$ concentration of NP5 was effective in killing Staphylococcus aureus, ESBL-producer Escherichia coli and MRSA.

These differences in effectiveness may be due to the composition of each natural preparation and also to the susceptibility of each bacterial isolate. Further research studies could elucidate this statement.

Management of the diabetic wounds/ulcers infection should not be limited to local wounds care but may involve other modalities including systemic antibiotics, debridement and revascularization whenever needed. However the topical care of wounds still remains a matter of debate, and an ideal dressing for these wounds has not yet been discovered. In the developing world a reluctance to stay with simple and still effective methods, treatments, and equipment, in order to 'catch up' with the developed world, comes at a cost. For instance, Postmes and Vandeputte [24] suggested that honey could be used instead of high-tech products such as the new recombinant growth factors. Honey and plant extractions used together have been reported to protect against toxicity [25]. As far as we can tell, no literature refers to the costeffectiveness of honey and herbal medicines in diabetic wound management. This may receive low priority in modern protocols, but should rate highly in resource-based health delivery. Further research is needed to elucidate and optimize the effective combination of these natural products in clinical practice. Neither of these natural products has an adverse effect on tissues, so they can safely be used on wounds and inserted into cavities to clear infection.

\section{ACKNOWLEDGMENTS}

The authors would like to express their thanks and appreciation to "Sheikh Mohammad Hussein Al-Amoudi Chair for Diabetic Foot Research" for funding of this study. Our thanks extend to Dr Asef Fatani and his colleagues in clinical microbiology laboratory of KAU hospital for conducting the related tests in KAUH laboratory.

\section{CONFLICT OF INTEREST}

None declared

\section{REFERENCES}

[1] Elhadad TA, Al-Amoudi AA, Alzahrani AS. Epidemiology, Clinical and Complications Profile of Diabetes in Saudi Arabia: A Review. Ann Saudi Med 2007; 4: 241-50.

[2] Egede LE, Ye X, Zheng D, Silverstein MD. The prevalence and pattern of complementary and alternative medicine use in individuals with diabetes. Diabetes Care 2002; 25(2): 324-9.

[3] Garrow D, Egede LE. National patterns and correlates of complementary and alternative medicine use in adults with diabetes. J Altern Complement Med 2006; 12(9): 895-902.

[4] Modak M, Dixit P, Londhe J, Ghaskadbi S, Paul A, Devasagayam $\mathrm{T}$. Indian herbs and herbal drugs used for the treatment of diabetes. J Clin Biochem Nutr 2007; 40(3): 163-73 
[5] Al Zahrani HA, Ghandourah NM, Merdad HT. Limb Amputations in Western Saudi Arabia. Asian J Surg 1992; 15(3): 119-22.

[6] Robbins JM, Strauss G, Aron D, Long J, Kuba J, Kaplan Y. Mortality rates and diabetic foot ulcers: is it time to communicate mortality risk to patients with diabetic foot ulceration? J Am Podiatr Med Assoc 2008; 98(6): 489-93.

[7] Zgonis T, Stapleton JJ, Girard-Powell VA, Hagino RT. Surgical management of diabetic foot infections and amputations. AORN J 2008; 87(5): 935-46.

[8] Tentoulouris N, Al-Sabbagh S, Walker MG, Boulton AJM, Jude EB. Mortality in Diabetic and non-diabetic patients after amputations performed from 1990 to 1995. Diabetes Care 2007; 27: 1598-604.

[9] Schofield CJ, Libby G, Brennan GM, Macalpine RR, Morris AD, Leese G. Mortality and hospitalizations in patients after amputations. Diabetes Care 2006; 29(10): 2252-6.

[10] Khanolkar MP, Bain SC, Stephens JW. The diabetic foot. QJM 2008; 101(9): 685-95.

[11] Boutoille D, Feraille A, Maulaz D, Krempf M. Quality of life with diabetes-associated foot complications: comparison between lower limb amputations and chronic foot ulceration. Foot Ankle Int 2008; 29(11): 1074-8.

[12] Modak M, Dixit P, Londhe J, Ghaskadbi S, Paul A, Devasagayam T. Indian herbs and herbal drugs used for the treatment of diabetes. J Clin Biochem Nutr 2007; 40(3): 163-73.

[13] Allen KL. The potential for using honey to treat wounds infected with MRSA and VRE. First World Wound Healing Congress; Melbourne, Australia. September 12-13, 2000.

[14] Vardi A, Barzilay Z, Linder N, et al. Local application of honey for treatment of neonatal postoperative wound infection. Acta Paediatr 1998; 87: 429-32.
[15] Molan PC. The antibacterial properties of honey. Chem NZ 1995; 59: $10-4$.

[16] Tonkal AM, Morsy TA. An update review on Commiphora molmol and related species. J Egypt Soc Parasitol 2008; 38(3): 763-96.

[17] Nomicos EY. Myrrh: medical marvel or myth of the Magi? Holist Nurs Pract 2007; 21(6): 308-23.

[18] Dolara P, Corte B, Ghelardini C, et al. Local anaesthetic, antibacterial and antifungal properties of sesquiterpenes from myrrh. Planta Med 2000; 66(4): 356-8.

[19] Ali BH, Blunden G. Pharmacological and toxicological properties of Nigella sativa. Phytother Res 2003; 17(4): 299-305.

[20] Salem ML. Immunomodulatory and therapeutic properties of the Nigella sativa L. seed. Int Immunopharmacol 2005; 5(13-14): 1749-70.

[21] Morsi NM. Antimicrobial effect of crude extracts of Nigella sativa on multiple antibiotics-resistant bacteria. Acta Microbiol Pol 2000; 49(1): 63-74.

[22] Tonks AJ, Cooper RA, Jones KP, et al. Honey stimulates inflammatory cytokine production from monocytes. Cytokine 2003; 21: 242-7.

[23] Tallarida RJ. Drug synergism: its detection and applications. J Pharmacol Exp Ther 2001; 298: 865-72.

[24] Postmes T, Vandeputte J. Recombinant growth factors or honey? Burns 1999; 25: 676-8.

[25] Shati AA, Elsaid FG, Hafez EE. Biochemical and molecular aspects of aluminium chloride-induced neurotoxicity in mice and the protective role of Crocus sativus L. extraction and honey syrup. Neuroscience 2011; 175: 66-74.

(C) Alzahrani et al.; Licensee Bentham Open.

This is an open access article licensed under the terms of the Creative Commons Attribution Non-Commercial License (http://creativecommons. org/licenses/ by-nc/3. 0/) which permits unrestricted, non-commercial use, distribution and reproduction in any medium, provided the work is properly cited. 